\title{
Nachruf auf Herrn OMR Prof. Dr. Hermann Kemmetmüller
}

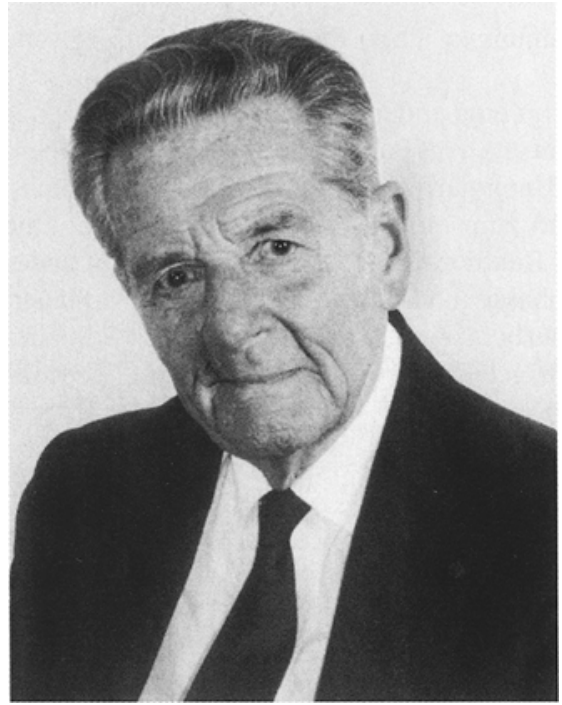

Soeben erreicht mich die traurige Nachricht, dass unser allseits verehrter Freund, Herr OMR Prof. Dr. Hermann Kemmetmüller am Sonntag, dem 20. Mai 2001 plötzlich verstorben ist.

Er war sicherlich eine der profiliertesten Persönlichkeiten der österreichischen Augenheilkunde und ein international anerkannter Kontaktologe. Die ständige Sorge um seine Patienten hat sein Leben erfüllt. In seinen Forschungen hat er sich speziell der Entwicklung der Kontaktlinse zugewandt. Sein wissenschaftliches Werk umfasst über 80 Publikationen. In regelmäßigen Kongressbesuchen hat er stets durch wohlgesetzte Vorträge aufhorchen lassen. Jahrelange unermüdliche Tätigkeit im Verband der Augenärzte und in der Ärztekammer haben sein standespolitisches Engagement gekennzeichnet.

Hermann Kemmetmüller wurde am 30. Oktober 1914 in Wien geboren, absolvierte die Schulen in Waidhofen/Ybbs und maturierte daselbst im Juni 1931. Das Medizinstudium, begann er in Wien und promovierte in Graz am 22. Dezember 1938 zum Doctor med. univ. Nach der Tätigkeit bei der Wehrmacht begann er die augenärztliche Ausbildung in Wien. Ab Oktober 1945 war er als Assistent an der I. Univ.Augenklinik unter Prof. Pillat und Prof. Safar tätig. Im Feber 1948 erfolgte die Verleihung des Facharzttitels. Im August 1947 wurde er an das 110 th Station Hospital berufen, dessen Augenabteilung er bis Oktober 1955 leitete. Ab Oktober 1955 führte er dann seine selbständige augenärztliche Praxis in Wien und war auch in Waid-hofen als Augenarzt tätig.
Im Mai 1976 habilitierte er zum Universitätsdozent unter besonderer Berücksichtigung der Kontaktlinsenforschung. Im Dezember 1975 wurde ihm der Berufstitel Obermedizinalrat verliehen. Im Juni 1983 wurde er zum a. o. Universitätsprofessor ernannt.

Das berufliche Leben von Hermann Kemmetmüller war geprägt von der Kontaktlinse. Schon während der Ausbildungszeit hat er mit seinen Studien über die Anpassung von Corneoscleralschalen zur Verbesserung des Sehvermögens bei Keratokonus begonnen. Diese Studien wurden an der I. Augenklinik in Wien durch die neuen PMMA-Materialien verfeinert. 1955 begann er seine ersten Untersuchungen zur Entwicklung der Corneallinse. 1959 wurde seine Anpassungsmethode der Mikrohornhautlinsen publiziert. Sein Interesse galt insbesondere der Verfeinerung der Kontaktlinsenanpassungsmethoden. Es sind ihm dabei wesentliche Fortschritte bei der Behandlung des Keratokonus sowie der Beinflussung der Myopie durch Kontaktlinsen und in der Entwicklung von Mehrstärkenkontaktlinsen gelungen.

Hermann Kemmetmüller ist ein weit über die Grenzen unseres Landes bekannter und anerkannter Ophthalmologe, Mitglied zahlreicher wissenschaftlicher Vereinigungen und Träger zahlloser in- und ausländischer Ehrungen: 1962 war er Mitbegründer der „European Contact Lens Society of Ophthalmologists“ (ECLSO), deren Vizepräsident er war. Er war auch Mitbegründer des „Verbandes der Augenärzte Österreichs", dessen Sekretär er durch 20 Jahre bis 1977 war. Weiters war er Mitglied der ÖOG, der DOG, der SOG und der Ophthalmologischen Gesellschaft in Wien, deren Präsident er 1972/73 war. Er war Träger des österreichischen Ehrenkreuzes für Wissenschaft und Kunst 1. Klasse sowie zahlreicher weiterer Medaillen und Auszeichnungen.

Ein geliebter Mensch, eine geachtete Persönlichkeit und ein guter Arzt ist von uns gegangen. Gerade für mich war er wie eine Vaterfigur und ich verdanke ihm außerordentlich viel: er hat mich wohlwollend in seiner Praxis aufgenommen und ich habe sehr viel von ihm gelernt. Ich war stets bemüht, sein Lebenswerk in seiner Praxis weiter aufzubauen und in seinem Sinne fortzuführen. So lange ich kann, werde ich dies auch weiterhin machen.

Er war ein stets pflichtbewusster und von all seinen Patienten geschätzter Arzt. Mit großem Pioniergeist hat er die Kontaktlinse in der Augenheilkunde etabliert, sodass sie heute nicht mehr wegzudenken ist. Jahrzehnte unermüdlicher Tätigkeit in Standespolitik und Wissenschaft, in Klinik und Praxis kennzeichneten seinen Lebensweg. Wir werden ihm ein ehrendes Angedenken bewahren.

Prim. Dr. Paul Drobec 